\title{
A STUDY ON THE ROLES OF IOT IN THE AGRICULTURE FOR SMART FARMING IMPLEMENTATIONS
}

\begin{tabular}{|c|c|c|c|}
\hline \multirow[b]{2}{*}{ Journal } & \multicolumn{3}{|c|}{$\begin{array}{c}\text { Dr. Ashok Kumar } \\
\text { SOA, Sanskriti University, Mathura, Uttar Pradesh, India }\end{array}$} \\
\hline & \multicolumn{3}{|c|}{$\begin{array}{l}\text { Samvakti Journal of Research in Information Technology } \\
\text { https://www.sjrit.samvaktijournals.com } \\
\text { Volume } 2 \text { Year of Volume } 2021 \text { Page No : } 41 \text { - } 48\end{array}$} \\
\hline Discipline & \multicolumn{3}{|l|}{ Internet of Things } \\
\hline Conference & \multicolumn{3}{|c|}{$\begin{array}{l}\text { A virtual international conference on redefining and transforming the role of higher } \\
\text { education in sustainable development }\end{array}$} \\
\hline Conference & \multicolumn{3}{|c|}{$\overline{\text { Start Date: September 30, } 2021}$} \\
\hline Dates & \multirow{2}{*}{\multicolumn{3}{|c|}{$\begin{array}{l}\text { End Date : September 30, } 2021 \\
\text { JAIN (Deemed-to-be University) in association with Council for Industrial } \\
\text { Innovation and Research }\end{array}$}} \\
\hline Institute Name & & & \\
\hline $\begin{array}{l}\text { Date Received } \\
\text { ID } \\
\text { Dol }\end{array}$ & $\begin{array}{l}\text { November } 19,2021 \\
2021.02 .15 \\
10.46402 / 2021.02 .15\end{array}$ & $\begin{array}{l}\text { Publication Date } \\
\text { Paper Type } \\
\text { Dol URL }\end{array}$ & $\begin{array}{l}\text { : December } 11,2021 \\
\text { : Conference Paper } \\
\text { : https://dx.doi.org/10.46402/2021.02.15 }\end{array}$ \\
\hline
\end{tabular}

\section{ABSTRACT}

The Internets of Thing (IOT) is a promising technique that may be used to modernize a multitude of industries at a low cost. Agriculture fields are being managed or monitored automatically or with minimal human involvement using loT based technologies. The article discusses a variety of technologies that are employed in the fields of the loT in agriculture. This covers the most significant aspects of the loT based smarts farming's. A comprehensive evaluation of the networks technology utilized in the loT based agricultural has been conducted, covering networks construction or layers, networking protocols, as well as protocols. The integration of the loT based farming production with crucial technologies like clouds computing, vast data storages, or analytic was also explored. In additions, issue about security in the loT farming have been highlights. A collection of the smart phones or sensor-based apps for many aspects of farm management is also available. Finally, numerous countries' legislation and regulations for standardizing loT-based farming have been presented, as well as a few publicly available 
success stories. Finally, a number of pressing research issues and challenges in the fields of the loT agriculture were reviewed.

KEYWORDS: IoT, Network, Protocols, Platforms, Smart Farming, Security.

\section{INTRODUCTION}

The Auto ID center at the MIT or its related markets research papers drew attention to the Internet of Thing idea in 1999. Essentially, the Internets of the Thing (IoT) is an interconnection of numerous objects that communicate, perceive, or interacts with their internally or externally state via embedded technologies. The Internet of Things (IoT) has emerged as just a megatrend for next generations technology that has the ability to impact the whole business spectrum by allowing end device, system, and services to communicate more effectively. Smart health care, smarts cities, safety, retails, traffics congestion, industrial controls, and farming are just a lot of small fields where the Internets of Things might be beneficial. In order to create smart farming solutions, a considerable amounts of the works has been done using loT technology in the agricultural sector. By analyzing various difficulties and difficulties in the farming's, the Internets of Thing has created a significant transformations in the agricultural environment.

With the advancement of technology, agriculturalists or technologists are now expected to use loT to find answers to problems that farmer face, including such water crisis, cost managements, even productivity issues. Cutting-edge loT technology has recognized all of these issue or certain solution to the rise productivity although lowering expenses. Due to the effort being finished on the wireless sensor networks, people may acquire data from detecting devices or transfer it to the central server. Sensors data offers information on various environmental variables, allowing for proper monitoring of the entire systems. Monitoring ecological situations or crops output is not only factors that influences agricultural output; there are more, including field managements, soils as well as crops monitoring, unwanted item migrations, wild animal attacks, and thefts, to mention a few. Besides, loT allow for well-ordered scheduling of the limited resource, ensuring that best used of loT improves productivity. the agricultural trend that provide easy or costs effectives interactions through secure but instead unblemished connectivity across personal Greenhouse, Livestock's, Farmers, or Fields monitoring Using wireless devices, Internet of Things agricultural network allow real-time crop and animal monitoring's ${ }^{[1]}$.

There are several application, protocols, or prototypes in agricultural sectors as whole. Effective use of technology, network design, application, security, or difficulties are all hot topics in loT agricultural research. Furthermore, various loT regulations and standards have been adopted in agriculture by several governments and organizations across the world. However, significants amounts of the works has been done in the loT agricultural setting, and a comprehensive study of loT in the agriculture is required to comprehend 
the present research state. The following Internet of Things agricultural methods have been included from the literature as a contribution to this research ${ }^{[2][3]}$.

- Present key component of the Internets of Things based smarts farmings together with the related technology in the Sections II.

- Sections III delves into the networks architecture of the Internet of Things, including network architecture or layers, network topologies, and device or protocol utilized in the agricultural Internet of Things.

- In Section IV, several applications areas and related smart phone or sensors based application were addressed.

- In the Sections, security or privacy concerns in loT based agriculture were addressed.

- The industrial trends are addressed in Section VI, which includes information on the leading technological companies that are investing in this field.

- In Section VII, various nations' loT agricultural policies for standardization of IoTbased agriculture were addressed. This section also includes a few examples of success in this field.

- Finally, Section VIII discusses the outstanding problems and challenges of improving loT-based agricultural technology from a variety of perspectives.

\section{Relevant Technologies and Major Components for the IoT Based Smarts Farming:}

Major Internet of Thing based Smarts Agriculture Components there are four main component of the loT based Smart farmings Physical structure, data collection, data process as well as data analytic are the four main components. To prevent any unfavorable outcomes, the physical structure is most essential element in precisions agriculture. The whole system is intended to control the sensors, actuators, and gadgets. Soil sensing, temperature Sensing, climate sensing, lights sensing, or moistures sensing are all functions that a sensor may accomplish. Devices, too, provide a variety of control tasks, such as nodes discovery, devices identification, or naming services, among others. Any other devices \& sensor that is control by the microcontroller may perform all of these tasks. This controlling action may be carried out by the any remotes devices and computer linked to the Internet. Images or videos process, data loadings, management information systems, or data mining's are all aspects of data processing. Any feature that may operate in parallel to offer additional services can be introduced based on the system needs. Monitoring and managing are the two primary aspects of data analytics. Field monitoring applications, on the other hand, are designed to report various field parameters such as soils richness, temperatures, pressure, humidity, gas, (air or water pressure), as well as crops disease monitoring ${ }^{[4]}$. 


\section{Agriculture-Related loT Technologies:}

Because there are so many technologies utilized in loT agricultural solutions that it's difficult to list them all, our talk focused on a few key technologies that have helped modernize loT agricultural services.

- Computing in the Cloud and at the Edge in agriculture, IoT and cloud computing collaboration offers ubiquitous access to common resources. Cloud computing is critical for meeting different agricultural requirements on demand via the network and executing activities. A clouds based software's architectures has been suggested for more the correct processing or retrieval of the information's as well as agricultural activities.

- Machine learning and big data analytics Agricultural sensors produce a huge quantity of important data, which is referred to as big data. At various phases, big data analysis offers various or effective crops monitoring techniques. There has been a thorough study of the big information investigation in the farming. Neural network are the familiar for the providing optimum answers at a rapid rate.

- Robotics Agribot have been created for aim of the smart farmings, reducing the number of farmer required by the improving work pace using advanced methods. Agribots conduct basic tasks like as weeding, spraying, and planting. To improve agricultural production and effective resource use, all of these robots are controlled by loT. For characterization and ground mapping, a multisensor robot's method has been suggested.

\section{Agricultural lot Networks}

One of most important aspect of the loT in agriculture is the loT agricultural networks, and loT networks for the agriculture. It aids in monitoring of agricultural data as well as the transmission and receipt of such data. The framework includes Internet of Things farming networks architectures, loT agricultural networks platform, or the loT farming networks topologies as well as protocols ${ }^{[5][6]}$.

\section{Agricultural Internet of Things Network Architecture:}

The key element of IoT in agriculture is loT agricultural networks. And IoT Agricultural Networks Architecture proposes a framework for describing the physical components of loT agricultural networks, as well as the operating principles and methods. Because of ubiquity or interoperability of the IP, most loT systems follows the four layer design (Networks Layer, Application Layers, Physical or Mac Layers, or Transports Layer), as proposed by Naik (Figure 1).

Following our examination of these four layers protocols, we looked at two additional approaches: IPv6 and 6LoWPAN. This is the highest degree of abstraction, allowing for 
the creation of numerous user application. At this layers, communications protocols are implemented to monitor various agricultural factor such as the meteorological data, soils moistures levels, irrigations monitoring, and so on.

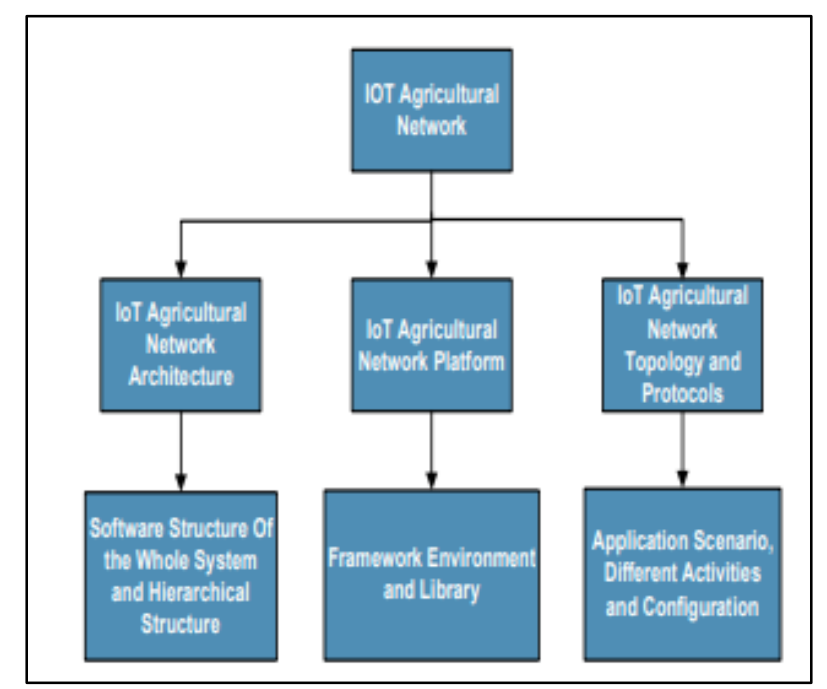

Figure 1: Illustrate the loT Agricultural Network.

\section{Agricultural Challenges in the Internet of Things:}

Several researcher have worked on the loT agriculture systems, developing or creating different IoT agricultural solutions to address a variety of technical and architectural challenges. Furthermore, there are many outstanding problems and difficulties that need to be addressed efficiently, according to the research's points of view in the literatures. There are many difficulties associated with the implementation and use of IoT smart agricultural applications. This study uncovered a number of loT agricultural problems and challenges, both known and undiscovered ${ }^{[7][8]}$.

\section{Hardware Issues:}

A lot of challenges arise in an loT agriculture setting. To start with, the apparatus at the perceptual layer is primarily exposed to extreme weather conditions such as rain, greater temperatures, extreme humidity, strong winds, and a range of other possible risks that might harm electronic circuits. In order to work continuously for a long period, consumer devices rely on the sufficient battery power supplies.

\section{Networking Obstacles:}

These difficulties occur not just at the hardware level, but also at the network layer. Wireless connectivity is critical for adoption of the loT based agriculture due to the increasing price of wiring. Human existence, temperature, humidity, as well as several others barriers insides space at which a wireless devices and node wishes to speak show 
that accepted transmitters performance is blown out of proportion by the humans occurrence, temperature, humidity, or several others barriers insides the space where a wireless devices as well as nodes want to the communicates.

Agricultural Platforms in the Internets of Things (IoT) In comparison to other loT end device, agriculture loT architecture is more complex and necessitates a real-time monitoring program with much more rigorous criteria. A custom-made computing platforms with run time libraries is required for this. A services oriented architecture may also be used to create suitable platform; these services can be accessed via various APIs. Furthermore, suitable frameworks as well as libraries should be the created so that agricultural developers may makes effective utilization of existing documents, class, scripts, and others relevant information ${ }^{[0][10] .}$

\section{DIscussion}

The Internets of Things (IOT) is promising methods that may be used to modernize a range of industries at a low cost. Agricultural fields are being managed and monitored automatically and with minimal human involvement using loT based technologies. The article discusses a variety of technologies that are utilized in the area of the IoT in the agriculture. It covers the most important aspects of IOT based smarts farming. The networks technologies used in the IOT based agricultures have been thoroughly examined, including networks infrastructure including layers, networks topologies, or protocol. This page also provides a thorough overview of current and future advancements in loT application areas, devices/sensors, networking devices, and just a range of other new technologies. This research analyzes a range of loT agricultural issues and security requirements in order to get a better knowledge of loT smarts farming security. Several essential elements of the loT based agriculture, including technology, market trends, and national laws, have also been given to help various stakeholders. The government has started to promote the Internet of the Things in the farming, the anticipated that the Internets of Thing will soon alter the conventional farming's techniques. Several major companies have also started to invest in and develop new loTbased agricultural management techniques. Finally, academics, experts, agriculturists, including policymakers engaged in and working in the loT and agricultural technology are likely to find this comprehensive research to be very useful.

\section{CONCLUSION}

Scientists from all around the worlds are experimenting with the loT technologies to the improves farming production in manner that complement current service area. Researcher have provided a thorough assessment of the state of the arts for loT in the agricultures in this post. To that aim, we'll talk about agricultural networks design, 
platform, or topology, which may assist farmers get access to loT backbones or improves crops production. This article also provides a thorough overview of existing or future advances in the loT smart farming, device/sensors, communications procedures, or a range of other modern technologies. For a greater understanding of the loT based smarts farming security, this study examines diversity of the loT agricultural problems or security needs. In addition, several key aspects of loT based agriculture, such as technology, industry trends, or country regulations, have been provided to assist different stakeholders. The government has begun to support Internet of Things in the agriculture, or it is expected that the Internet of Things in the agricultural will soon revolutionize traditional farmings methods. It's also apparent that several large corporations have begun to invest in and create innovative loT-based farm management methods. Finally, academics, professional, agriculturists, or policymakers who are involved or workings in the loT area or agricultural technology are anticipated to find this thorough study to be a very valuable piece of information. 


\section{REFERENCES:}

[1] M. S. Mekala and P. Viswanathan, "A Survey: Smart agriculture loT with cloud computing," 2017, doi: 10.1109/ICMDCS.2017.8211551.

[2] G. Witjaksono, A. A. Saeed Rabih, N. B. Yahya, and S. Alva, "IOT for Agriculture: Food Quality and Safety," 2018, doi: 10.1088/1757-899X/343/1/012023.

[3] P. P. Ray, "Internet of things for smart agriculture: Technologies, practices and future direction," J. Ambient Intell. Smart Environ., 2017, doi: 10.3233/AIS-170440.

[4] O. Elijah, T. A. Rahman, I. Orikumhi, C. Y. Leow, and M. N. Hindia, "An Overview of Internet of Things (IOT) and Data Analytics in Agriculture: Benefits and Challenges," IEEE Internet Things J., 2018, doi: 10.1109/JIOT.2018.2844296.

[5] V. N. Malavade and P. K. Akulwar, "Role of loT in Agriculture," Natl. Conf. "Changing Technol. Rural Dev., 2016.

[6] A. Nayyar and V. Puri, "Smart farming: lot based smart sensors agriculture stick for live temperature and moisture monitoring using arduino, cloud computing \& solar technology," 2017, doi: 10.1201/9781315364094-121.

[7] C. S. Nandyala and H. K. Kim, "Green loT Agriculture and Healthcare Application (GAHA)," Int. J. Smart Home, 2016, doi: 10.14257/ijsh.2016.10.4.26.

[8] N. Ahmed, D. De, and I. Hussain, "Internet of Things (IoT) for Smart Precision Agriculture and Farming in Rural Areas," IEEE Internet Things J., 2018, doi: 10.1109/JIOT.2018.2879579.

[9] A. Rojas, "Smart Agriculture loT with Cloud Computing," Rev. Hist. América, 2015.

[10] E. Y. T. Adesta, D. Agusman, and Avicenna, "Internet of things (IoT) in agriculture industries," Indones. J. Electr. Eng. Informatics, 2017, doi: 10.11591/ijeei.v5i4.373. 